Marquette University

e-Publications@Marquette

College of Education Faculty Research and

Publications

Education, College of

5-1-2004

Measuring Perceived Social Support in Mexican American Youth: Psychometric Properties of the Multidimensional Scale of Perceived Social Support

Lisa Edwards

Marquette University, lisa.edwards@marquette.edu

Accepted version. Hispanic Journal of Behavioral Sciences, Vol. 26, No. 2 (May 2004): 187-194. DOI.

(C) 2004 SAGE Publications. Used with permission. 


\title{
Measuring Perceived Social Support in Mexican American Youth: Psychometric Properties of the Multidimensional Scale of Perceived Social Support
}

\author{
Lisa M. Edwards \\ Department of Psychology, University of Notre Dame \\ Notre Dame, IN
}

The utility of the Multidimensional Scale of Perceived Social Support (MSPSS) (Zimet, Dahlem, Zimet, \& Farley, 1988) was investigated within a sample of 290 Mexican American adolescents. Results suggested that the three-subscale structure (Family, Friends, and Significant Other) of the MSPSS was confirmed, and adequate internal reliability for the three scales was demonstrated as well. Support for construct validity was found by evaluating correlations from a perceived family support subscale as well as a satisfaction with family measure. It appears that the MSPSS is a useful measure for assessing perceived social support in Latino youth and as such can be used to further our understanding about social support from different sources in Latino adolescents.

Latino adolescents are an increasing presence in U.S. communities. It is projected that by the year 2025, Hispanic 
Americans will account for $18 \%$ of the U.S. population, and by 2020 , one in five children will be Hispanic (U.S. Census Bureau, 2001). Social support may play a particularly important role in the lives of Latino adolescents, who are often navigating the challenges of acculturation, social development, and other processes. Social support, which can come from family, peers, and friends, can be a critical resource for Latino youths as they grow into adulthood.

Researchers investigating perceived social support in Latinos must be careful to select measures that have demonstrated adequate psychometric properties within Latino populations. The Multidimensional Scale of Perceived Social Support (MSPSS; Zimet, Dahlem, Zimet, \& Farley, 1988) was originally developed to assess social support in undergraduate students. Support for the threesubscale factor structure, internal reliability, and discriminant validity has been shown in undergraduates, adolescents living in Europe, and pregnant women (Zimet, Powell, Farley, Werkman, \& Berkoff, 1990); psychiatric outpatients (Cecil, Stanley, Carrion, \& Swann, 1995); and adolescents on an inpatient psychiatry unit (Kazarian \& McCabe, 1991). In a recent study, Canty-Mitchell and Zimet (2000) found support for the reliability and validity of the MSPSS with a sample of urban, primarily African American adolescents.

Although the growing body of research about the utility of the MSPSS suggests that it is a useful measure for many populations, its psychometric properties have yet to be investigated within Latino adolescents. The purpose of the present study is to investigate the reliability and validity of the MSPSS within a sample of Mexican American adolescents.

\section{Method}

\section{Participants}

Participants in this study were 290 English-speaking middle and high school students from the following states: California $(68 \% ; n=$ $198)$, Kansas $(27 \% ; n=78)$, and Texas $(5 \% ; n=14)$. Of this sample of 290 self-identified Mexican American youths, 164 (57\%) were girls and 126 (43\%) were boys. Participants ranged in age from 11 to 18 years, with a mean age of 15 years, and $80 \%$ identified as Catholic. The participants completed a demographic questionnaire about age,

Hispanic Journal of Behavioral Sciences, Vol. 26, No. 2 (May 2004): pg. 187-194. DOI. This article is (C SAGE Publications and permission has been granted for this version to appear in e-Publications@Marquette. SAGE Publications does not grant permission for this article to be further copied/distributed or hosted elsewhere without the express permission from SAGE Publications. 
race/ethnicity, and religious affiliation, as well as several measures as part of a larger study about adolescent well-being.

\section{Materials}

The MSPSS (Zimet et al., 1988) is a 12-item scale that measures perceived support from three domains: family, friends, and a significant other. Participants completing the MSPSS are asked to indicate their agreement with items on a 7-point Likert-type scale, ranging from very strongly disagree to very strongly agree. Total and subscale scores range from 1 to 7 , with higher scores suggesting greater levels of perceived social support. Canty-Mitchell and Zimet (2000) assessed the readability of the MSPSS items and found them to be at a fourth-grade reading level.

Adequate psychometric properties have been found with the MSPSS in several studies with young adults and adults in the United States and in Europe (Kazarian \& McCabe, 1991; Zimet et al., 1988, 1990). Canty-Mitchell and Zimet (2000) investigated the MSPSS with a sample of urban adolescents and found internal reliability estimates of .93 for the total score and .91, .89, and .91 for the Family, Friends, and Significant Others subscales. Factor analysis of the MSPSS with their sample confirmed the three-factor structure of the measure.

The Familism Scale (Sabogal, Marin, Otero-Sabogal, Marin, \& Perez-Stable, 1987) was developed to assess three aspects of familism in Latinos: familial obligations, perceived support from the family, and family as referents. Internal reliability coefficients for each subscale were .76, .70, and .64 within a sample of 452 Latino adults. The Perceived Support From Family subscale, which consists of three items assessing perceived support from family, was included in the present study as a measure of discriminant validity.

The Multidimensional Students' Life Satisfaction Scale (MSLSS) (Huebner, 1994) was designed to assess life satisfaction in adolescents across five specific domains (family, friends, school, living environment, and self), as well as overall life satisfaction. This 40 -item self-report instrument asks respondents to indicate their agreement with statements on a 6-point Likerttype scale, ranging from strongly disagree to strongly agree. Studies with the MSLSS suggest that this measure has acceptable psychometric properties. Internal reliability estimates for the total life satisfaction score were .91 and for the five domains ranged from .84 to .86 for Family, .82 to .85 for Friends, .84

Hispanic Journal of Behavioral Sciences, Vol. 26, No. 2 (May 2004): pg. 187-194. DOI. This article is @ SAGE Publications and permission has been granted for this version to appear in e-Publications@Marquette. SAGE Publications does not grant permission for this article to be further copied/distributed or hosted elsewhere without the express permission from SAGE Publications. 
NOT THE PUBLISHED VERSION; this is the author's final, peer-reviewed manuscript. The published version may be accessed by following the link in the citation at the bottom of the page.

to .85 for School, .78 to .79 for Living Environment, and .77 to .84 for Self. Test-retest reliability estimates, across a 4-week period, were .81 for the total score and .53 (Self) to .81 (Living Environment) for the domains. For the purpose of investigating convergent validity in the present study, the Satisfaction With Family subscale was used.

\section{Procedure}

Potential participants were solicited from the League of United Latin American Citizens (LULAC) National Educational Service Centers, public and private schools, and federal TRIO (i.e., Upward Bound, Upward Bound Math/Science, and Educational Talent Search) programs in several states across the United States. The researcher discussed the project with administrators and other staff members to obtain initial approval to solicit participants and provided all the materials for the schools and organizations. In some cases, the researcher went to the sites to administer the surveys once parental consent forms were obtained, and in other cases, the site staff administered the surveys and returned them to the researcher via mail.

Once consent was obtained from parents, students who volunteered to participate in the study were asked for assent and administered a packet of materials during a 40-minute period of school or of an after-school program. Students were informed of the purpose of the study (to better understand adolescent well-being) and were told that their participation was voluntary and they could withdraw from the study at any time.

\section{Results}

\section{Descriptive Statistics}

The means and standard deviations for the total MSPSS and the three subscales are presented in Table 1. As can be seen, the means for the subscales were as follows: Total $(M=5.58, S D=1.17)$, Family $(M=5.43, S D=1.36)$, Friends $(M=5.49, S D=1.38)$, and Significant Other $(M=5.83, S D=1.59)$. Mean levels of total social support and support from Family, Friends, and Significant Other were comparable to previously reported levels (Dahlem, Zimet, \& Walker, 1991; Zimet et al., 1988, 1990). No significant gender differences were found for the subscale or total scores on the MSPSS.

Hispanic Journal of Behavioral Sciences, Vol. 26, No. 2 (May 2004): pg. 187-194. DOI. This article is @ SAGE Publications and permission has been granted for this version to appear in e-Publications@Marquette. SAGE Publications does not grant permission for this article to be further copied/distributed or hosted elsewhere without the express permission from SAGE Publications. 
NOT THE PUBLISHED VERSION; this is the author's final, peer-reviewed manuscript. The published version may be accessed by following the link in the citation at the bottom of the page.

\section{Reliability}

Internal reliability estimates (Cronbach's alpha) were calculated for the three subscales and the total scale (see Table 1). Both the Family and Friends subscales demonstrated high internal consistency (.88 and .90, respectively), whereas the Significant Other subscale demonstrated barely adequate reliability (.61). The Total MSPSS demonstrated high internal consistency with an alpha of .86.

\section{Factorial Validity}

An exploratory principal components analysis (PCA) with varimax rotation was conducted with all 12 items of the MSPSS. The three factors (Family, Friends, and Significant Other) were extracted, which accounted for $47.9 \%, 14 \%$, and $9.5 \%$ of the variance, respectively. Consistent with results from prior studies (Zimet et al., $1988,1990)$, each of the items loaded on the appropriate MSPSS subscales (Family, Friends, and Significant Other). See Table 2 for the varimax rotation factor matrix of the MSPSS items.

\section{Construct Validity}

To provide support for convergent validity, scores from the Perceived Support From Family subscale (Familism Scale; Sabogal et al., 1987) and the Family subscale of the MSPSS were correlated. As expected, results demonstrated a significant, positive correlation ( $r=$ .53, $p<.001)$.

Support for the discriminant validity of the Family subscale of the MSPSS was gained by investigating differences between correlation coefficients for the three MSPSS scales and the Perceived Support From Family subscale from the Familism measure. It was expected that the relationship between the Perceived Support From Family subscale (Familism measure) and the Family subscale of the MSPSS would be stronger than the relationship between the Perceived Support From Family subscale and the MSPSS Friends or Significant Other subscales. Results demonstrated that the Perceived Support From Family subscale correlated significantly with the MSPSS Family subscale $(r=.53, p<.001)$, the Friends subscale $(r=.30, p<.001)$, and the Significant Other subscale $(r=.29, p<.001)$. The correlation between the Perceived Support From Family subscale and the MSPSS Family subscale was significantly stronger than the correlations with 
the MSPSS Significant Other $(t=-4.70, p<.001)$ and Friends $(t=-$ $4.33, p<.001$ ) subscales.

Further support for the construct validity of the MSPSS was sought using the Satisfaction With Family subscale of the MSLSS (Huebner, 1994). It was expected that the relationship between the Satisfaction With Family subscale of the MSLSS and the MSPSS Family subscale would be stronger than the relationship between the MSLSS Satisfaction With Family scale and the MSPSS Friends or Significant Other subscales. Results demonstrated that the Satisfaction With Family MSLSS subscale correlated significantly with the MSPSS Family subscale $(r=.71, p<.001)$, the Friends subscale $(r=.29, p<.001)$, and the Significant Other subscale $(r=.28, p<.001)$. The correlation between the Satisfaction With Family MSLSS subscale and the Family subscale of the MSPSS was significantly stronger than the correlations with the Friends $(t=-9.39, p<.001)$ or Significant Other $(t=-$ $10.07, p<.001$ ) subscales of the MSPSS, demonstrating support for discriminant validity of the MSPSS Family subscale.

\section{Discussion}

Results from this investigation of the MSPSS with Mexican American adolescents suggest that the MSPSS is a useful measure for assessing perceived support. Explanatory factor analysis suggested that the three-factor subscale structure (family, friends, and significant other) was replicated within this sample of Mexican American youths, providing support for the content validity of this scale. Furthermore, high internal reliability was found for the Total scale and Family and Friends subscales, but only barely adequate reliability was found for the Significant Other subscale. Future investigations should attempt to replicate these findings to evaluate the internal consistency of this subscale again.

Construct validity of the MSPSS was assessed by evaluating relationships with the Perceived Support From Family subscale of a Familism measure and the Satisfaction With Family scale of the MSLSS. Support for convergent validity was demonstrated as these two subscales were significantly, positively correlated with the MSPSS Family subscale. Discriminant validity was demonstrated through significantly stronger correlations between the MSPSS Family subscale and the Perceived Support From Family subscale than the MSPSS Friends or Significant Other subscales. Further support for discriminant

Hispanic Journal of Behavioral Sciences, Vol. 26, No. 2 (May 2004): pg. 187-194. DOI. This article is (C SAGE Publications and permission has been granted for this version to appear in e-Publications@Marquette. SAGE Publications does not grant permission for this article to be further copied/distributed or hosted elsewhere without the express permission from SAGE Publications. 
validity was found with significantly stronger correlations between the MSLSS Satisfaction With Family scale and the MSPSS Family subscale than the Friends or Significant Other subscales.

In contrast to prior research that has demonstrated women's higher levels of perceived social support from friends and significant others (Canty-Mitchell \& Zimet, 2000; Zimet et al., 1988), no gender differences were found on any of the subscales within this sample of Latino youths. Future research with Latino adolescents should again assess for gender differences to better understand these unique findings.

The present study provided reliability and validity support for the use of the MSPSS with Latino adolescents; however, it is important to note that the sample was entirely Mexican American. Because of within-group differences, researchers have suggested that Latino individuals be studied within their particular groups (e.g., Mexican American, Colombian, etc.) rather than group Latinos into one collective ethnic group (Umana-Taylor \& Fine, 2001). Thus, future studies should attempt to replicate these findings with other Latino groups to further our understanding of the utility of social support measures with individuals from diverse racial and ethnic groups.

The MSPSS appears to be a psychometrically reliable and valid instrument for use with Latino adolescents. As such, researchers investigating perceived social support in Latino youths can use this measure for studies about perceived support from family, friends, and significant others and, it is hoped, advance our understanding of social support in this growing population.

\section{Author}

Lisa M. Edwards received her doctorate in counseling psychology from the University of Kansas. She is currently a research associate in the Department of Psychology at the University of Notre Dame. Her research interests include multiracial issues, Latino/a psychology, and the applicability of positive constructs such as hope and subjective wellbeing to the lives of individuals from diverse cultural backgrounds.

\section{References}

Canty-Mitchell, J., \& Zimet, G. D. (2000). Psychometric properties of the Multidimensional Scale of Perceived Social Support in urban adolescents. American Journal of Community Psychology, 28, 391-400.

Hispanic Journal of Behavioral Sciences, Vol. 26, No. 2 (May 2004): pg. 187-194. DOI. This article is (C SAGE Publications and permission has been granted for this version to appear in e-Publications@Marquette. SAGE Publications does not grant permission for this article to be further copied/distributed or hosted elsewhere without the express permission from SAGE Publications. 
NOT THE PUBLISHED VERSION; this is the author's final, peer-reviewed manuscript. The published version may be accessed by following the link in the citation at the bottom of the page.

Cecil, H., Stanley, M. A., Carrion, P. G., \& Swann, A. (1995). Psychometric properties of the MSPSS and NOS in psychiatric outpatients. Journal of Clinical Psychology, 51, 593-602.

Dahlem, N. W., Zimet, G. D., \& Walker, R. R. (1991). The Multidimensional Scale of Perceived Social Support: A confirmation study. Journal of Clinical Psychology, 47, 756-761.

Huebner, E. S. (1994). Preliminary development and validation of a multidimensional life satisfaction scale for children. Psychological Assessment, 6, 149-158.

Kazarian, S. S., \& McCabe, S. B. (1991). Dimensions of social support in the MSPSS: Factorial structure, reliability, and theoretical implications. Journal of Community Psychology, 19, 150-160.

Sabogal, F., Marin, G., Otero-Sabogal, R., Marin, B. V., \& Perez-Stable, E. J. (1987). Hispanic familism and acculturation: What changes and what doesn't? Hispanic Journal of Behavioral Sciences, 9, 397-412.

Umana-Taylor, A. J., \& Fine, M. A. (2001). Methodological implications of grouping Latino adolescents into one collective ethnic group. Hispanic Journal of Behavioral Sciences, 23, 347-362.

U.S. Census Bureau. (2001). The Hispanic population: Census 2000 brief. Washington, DC: Department of Commerce, Economics and Statistical Administration.

Zimet, G. D., Dahlem, N. W., Zimet, S. G., \& Farley, G. K. (1988). The Multidimensional Scale of Perceived Social Support. Journal of Personality Assessment, 52, 30-41.

Zimet, G. D., Powell, S. S., Farley, G. K., Werkman, S., \& Berkoff, K. A. (1990). Psychometric characteristics of the Multidimensional Scale of Perceived Social Support. Journal of Personality Assessment, 55, 610617.

\section{Appendix}

Table 1: MSPSS ${ }^{a}$ Means, Standard Deviations, and Internal Reliability Estimates $(N=290)$

\begin{tabular}{lccc}
\hline MSPSS Subscale & $M$ & $S D$ & Internal Reliability \\
\hline Family & 5.43 & 1.36 & .88 \\
Friends & 5.49 & 1.38 & .90 \\
Significant Other & 5.83 & 1.59 & .61 \\
Total scale & 5.58 & 1.17 & .86 \\
\hline
\end{tabular}

a. MSPSS $=$ Multidimensional Scale of Perceived Social Support.

Hispanic Journal of Behavioral Sciences, Vol. 26, No. 2 (May 2004): pg. 187-194. DOI. This article is (C SAGE Publications and permission has been granted for this version to appear in e-Publications@Marquette. SAGE Publications does not grant permission for this article to be further copied/distributed or hosted elsewhere without the express permission from SAGE Publications. 
NOT THE PUBLISHED VERSION; this is the author's final, peer-reviewed manuscript. The published version may be accessed by following the link in the citation at the bottom of the page.

\section{Table 2: Factor Loadings for Family, Friends, and Significant Other} Subscales of MSPSS

\begin{tabular}{|c|c|c|c|}
\hline \multirow[b]{2}{*}{ MSPSS Item } & \multicolumn{3}{|c|}{ Factor } \\
\hline & Family & Friends & Significant Other \\
\hline \multicolumn{4}{|l|}{ Family } \\
\hline 3. My family really tries to help me. & .824 & .200 & .236 \\
\hline $\begin{array}{l}\text { 4. I get the emotional heip and support } \\
\text { that I need from my family. }\end{array}$ & .836 & .112 & .282 \\
\hline $\begin{array}{l}\text { 8. I can talk about my problems with my } \\
\text { family. }\end{array}$ & .786 & .089 & .297 \\
\hline $\begin{array}{l}\text { 11. My family is willing to help me make } \\
\text { decisions. }\end{array}$ & .808 & .319 & .052 \\
\hline \multicolumn{4}{|l|}{ Friends } \\
\hline 6. My friends really try to help me. & .166 & .827 & .238 \\
\hline $\begin{array}{l}\text { 7. I can count on my friends when things } \\
\text { go wrong. }\end{array}$ & .143 & .874 & .189 \\
\hline $\begin{array}{l}\text { 9. I have friends with whom I can share } \\
\text { my joys and sorrows. }\end{array}$ & .216 & .785 & 307 \\
\hline $\begin{array}{l}\text { 12. I can talk about my problems with my } \\
\text { friends. }\end{array}$ & .177 & .829 & .190 \\
\hline \multicolumn{4}{|l|}{ Significant Other } \\
\hline $\begin{array}{l}\text { 1. There is a special person who is } \\
\text { around when I am in need. }\end{array}$ & .184 & .238 & .814 \\
\hline $\begin{array}{l}\text { 2. There is a special person with whom I } \\
\text { can share joys and sorrows. }\end{array}$ & .261 & .177 & .830 \\
\hline $\begin{array}{l}\text { 5. I have a special person who is a real } \\
\text { source of comfort to me. }\end{array}$ & .114 & .099 & .440 \\
\hline $\begin{array}{l}\text { 10. There is a special person in my life } \\
\text { who cares about my feelings. }\end{array}$ & .287 & .291 & .711 \\
\hline
\end{tabular}

a. MSPSS = Multidimensional Scale of Perceived Social Support.

Hispanic Journal of Behavioral Sciences, Vol. 26, No. 2 (May 2004): pg. 187-194. DOI. This article is (C SAGE Publications and permission has been granted for this version to appear in e-Publications@Marquette. SAGE Publications does not grant permission for this article to be further copied/distributed or hosted elsewhere without the express permission from SAGE Publications. 